Article

\title{
Development of Algae Guard Façade Paint with Statistical Modeling under Natural Phenomena
}

\author{
Sheraz Ahmed Qureshi ${ }^{1, *}$, Amir Shafeeq ${ }^{1, *}$ (1) , Aamir Ijaz ${ }^{2}$ and Muhammad Moeen Butt ${ }^{3}$ \\ 1 Institute of Chemical Engineering \& Technology, University of the Punjab, Lahore 54590, Pakistan \\ 2 Muhammad Nawaz Sharif University of Engineering \& Technology, Multan 66000, Pakistan; \\ ijazaamir@yahoo.com \\ 3 Department of Quantitative Methods, University of Management and Technology, Lahore 54770, Pakistan; \\ muhammad.moeen@umt.edu.pk \\ * Correspondence: sheraz7_2000@yahoo.com (S.A.Q.); amirengr@gmail.com (A.S.)
}

Received: 12 September 2018; Accepted: 15 November 2018; Published: 29 November 2018

check for updates

\begin{abstract}
Algaecides are chemicals that cause serious health problems. Conventional paints contain algaecides to improve the algae resistance on the paint film. Present research has suggested an environment-friendly paint formulation that focuses on developing algae resistance without having algaecides. In this research, algae growth on newly developed paint is modeled by incorporating dirt resistance of paint and natural phenomena including humidity, temperature, and time, respectively. The fitted Model revealed explained variation of $59.65 \%$ in the average algae growth, of which, dirt resistance, humidity, temperature, and some of their interactions play significant role in this variation. The model suggests that the proposed newly developed paint without algaecides is more resistant to algae growth and significantly decreased the average algae growth rate by $0.53 \%$ as compared to conventional paints. Keeping the effect of all other factors constant, if dirt resistance of paint $\left(D_{\mathrm{c}}\right.$ value) increases by one percent, average algae growth decreases by $12.98 \%$; when temperature increases by $1{ }^{\circ} \mathrm{C}$, average algae growth decreases by $22.4 \%$; a positive unit change in the joint linear effect of dirt resistance, temperature, and humidity caused a decrease in average algae growth by $0.0031 \%$. It was also observed that the individual effect of the humidity variable was inversely related with average algae growth. However, the combination of humidity and temperature, humidity and dirt resistance, humidity and time, and the quadratic effect of humidity were found to increase the average algae growth rate. The cubic effect of temperature variable by one degree centigrade resulted in decrease of average algae growth by $0.000907 \%$.
\end{abstract}

Keywords: algaecides; dirt; humidity; resistant; temperature; time

\section{Introduction}

Paint is a semi-solid substance that is applied over a surface in the form of a thin layer [1]. There are two major functions of paint. One is protection and the other is decoration. It has been observed that fungi and bacteria usually develop on gloss paint films, whereas algae develop on water-based paints [2]. Algae, fungi, and bacteria are different from each other in terms of morphology and growth patterns. Algae are photosynthetic while others are not. Algae contains chlorophyll while fungi and bacteria both don't have chlorophyll. Fungi are generally big in size while bacteria are very minute in size. Algae, fungi, and bacteria can be distinguished by microscope. Due to the presence of different photosynthetic pigments, algae are found in different colors like green, red, brown, but mostly green in color. While fungi do not possess any photosynthetic pigment [3]. Algae are the highly diversified group of microorganisms identified as microalgae. They have been roughly enumerated as about ten million mostly microalgae [4]. Algal growth is affected by $\mathrm{pH}$ value. When $\mathrm{pH}$ was lowered 
from 6.6 to 5.0, algal abundance increased [5]. Reduced algae growth was observed in a group of $\mathrm{pH}$-tolerant algae when the $\mathrm{pH}$ exceeded 9.5 [6]. The algal growth is strongly influenced by the water supply, including the rain, the condensation, and high humidity [7]. Environmental factors e.g., humidity, temperature and dirt accumulation are major sources of algae accumulation on façade paints. The growth of microorganisms in paint causes many problems such as degradation of paint films, blistering, flaking and breakdown/cracking of the paint films [8]. Different allergies that could harm the brain or peripheral nervous system are caused by different cyanobacterial species. The other harmful effects are nerve ion-channel blocking, neuromuscular blockade, anti-acetyl cholinesterase activity, anti-phosphate activity and protein synthesis inhibition [9]. Symptoms due to cyanobacteria intake include abdominal pain, nausea, vomiting, diarrhea, sore throat, dry cough, headache, blistering of the mouth, atypical pneumonia and elevated liver enzymes in the serum [10]. The main objective of this paper is to develop algae resistive paint without any algaecide which is very harmful to ecosystems. TBT is a broad-spectrum algaecide [11]. TBT causes histopathological effects [12] and mortality [13]. TBT pollution can adversely affect whole populations [14]. Another algaecide is Diuron, which has adverse impacts on human health and environment [15]. It is a human carcinogen [16]. Carbendazim algaecide is identified as carcinogenic, mutagenic and teratogenic in experimental animals and the structure of animal cells $[17,18]$. Carbamates algaecide hinders cellular metabolism including energy, protein, and nucleic acid metabolism and cause cell regression and death [19]. Zinc pyrithione (ZnPT) algaecide may reach to stem cells in human skin hair follicles [20]. Toxicity of zinc pyrithione results in iron starvation [21]. The most important chemical classes of algaecides used in paints are Tributyltin (TBT), Diuron, Carbendazim, Carbamates, Zinc pyrithione. TBT can induce histopathological effects and mortality [12,13]. TBT pollution is of serious concern as it has led to collapse of whole populations of organisms [14]. Diuron is a problematic water pollutant which has major impacts on human health and the environment. The diuron is absorbed from the gastrointestinal and respiratory systems [15]. The carbendazim is known to be carcinogenic, mutagenic and teratogenic in experimental animals and animal cell cultures $[17,18]$. The carbamates inhibit cellular metabolism including energy, protein, and nucleic acid metabolism, thereby, causing cell regression and death [19]. The zinc pyrithione was found to be highly toxic to aquatic plants and animals [22] as it could inhibit cell growth $[23,24]$.

It has been observed that anatase titanium dioxide could be used as a better preservative agent against biodegradation compared to general biocides and also offers better result than some of the conventional biocides [25]. It has also been observed that if a mixture of $75 \%$ anatase and $25 \%$ rutile titanium dioxide is used then the mixture could serve as a better preservative agent against biodegradation [26]. Another study shows that calcium carbonate could pose a negative impact on photocatalytic inhibition activity against bacterial accumulation [27]. Zinc oxide used in the paint formulations has been found to offer a unique property of self-cleaning of paint film in the presence of UV light [28]. The zinc oxide Nanoparticles show excellent antibacterial activity by breaking down the microbial pollutants in the form of carbon dioxide and water in the presence of ultraviolet light [29]. Zinc oxide nanoparticles are found to be useful for preventing dirt accumulation over the surface of the paint [30]. Dirt that is present on the façade painted surfaces promotes the growth of microorganisms providing the required nutrients. This growth can occur even at a lower equilibrium relative humidity (ERH) level [31-37].

Multiple Linear Regression Modeling is an appropriate statistical tool to explore the significant effect of independent variables and to predict the average response of the dependent variable. In case the model consists of a large number of potential predictors it is reasonable to use the stepwise regression procedures to determine the final model. The selection of the final model is made by comparing the models by using the criteria of adjusted $R^{2}$-Adj. values, Mallows [38] $C_{\mathrm{p}}$-values, Root Mean Square Error (RMSE) and Akaike Information Criteria (AIC) [39].

Algae grow in all temperatures and in moist conditions. Dirt are the source of nutrients for algae growth. The time factor, humidity, temperature and dirt accumulation are major sources of algae 
accumulation on façade paints. The present work has been carried out to meet two main objectives. First is to suggest a formulation of paint that could resist growth of algae without having algaecides. This newly developed environment-friendly paint must be at least equal in efficacy as those already available formulations containing harmful algaecides. The second objective is to explore a linear or non-linear relation which may be helpful in predicting the average algae growth rate on the basis of predictors including Time (number of days), $D_{\mathrm{c}}$, Temperature and Humidity.

\section{Material and Methods}

\subsection{Chemicals Used}

The chemicals used in sample preparation are as follows:

- $\quad$ Reverse Osmosis Treated Water, TDS 0.01, Hardness 4;

- Dispex A-40, Dispersant, solution of an ammonium salt of an acrylic polymer in water, BASF, Ludwigshafen, Germany;

- Magnesium Silicate, 65-micron particle size, Shaheen grinding mills, Lahore, Pakistan;

- Acrysol TT 615, Hydrophobically Modified Anionic Thickener, Rohm and Haas, Philadelphia, PA, USA;

- Zinc Oxide, Bruggemann chemical, Heilbronn, Germany;

- KA-100, Anatase Titanium Dioxide, Kimix, Hangzhou, China;

- $\quad \mathrm{TiO}_{2} 2310$, Rutile Titanium Dioxide, Kronos titanium, Dallas, TX, USA;

- Propylene Glycol, Dow, Horgen, Switzerland;

- Wacker 1306, Emulsion of a Polysiloxane Modified with functional Silicone Resin, Wacker, Munich, Germany;

- DisplairCF-245, Mineral Hydrocarbons Defoamer, Whitebirk Ind. Estate, Blackburn, UK;

- AMP-95, 95\%, 2-Amino-2-Methyl-1-Propanol Solution, Angus Chemie, GmbH, Ibbenbüren, Germany;

- $\quad$ PST-50A, Styrene Acrylic Copolymer Emulsion, Organic Kimya, Istanbul, Turkey.

\subsection{Preparation of Paint Sample}

Mill base slurry was prepared in Nano mill according to formulation as shown in Table 1. Output pneumatic pump pressure of Nano mill was adjusted between 0.2 to $0.4 \mathrm{MPa}$. Revolution per minute (rpm) of Nano mill shaft was adjusted at 2500. The output flow rate from Nano mill was regulated at $2 \mathrm{~g} / \mathrm{s}$. Fineness of Dispersion of the prepared slurry was determined by Hegman-Type Gage using the standard test ASTMD 1210 [40]. It was observed that the particle size was 10 microns. Paint was prepared using Nano slurry as per formula shown in Table 2 under conventional agitator. The revolution per minute (rpm) of agitator impeller was maintained at 1400 .

Table 1. Nano mill Slurry composition.

\begin{tabular}{ccc}
\hline Serial No. & Ingredients & Quantity $(\mathbf{g})$ \\
\hline 1 & ROW & 27.16 \\
2 & DIS & 0.84 \\
3 & AMP & 0.60 \\
4 & MS & 10.00 \\
5 & ZO & 5.00 \\
6 & ATD & 20.00 \\
7 & RTD & 7.00 \\
Total & - & 70.60 \\
\hline
\end{tabular}


Table 2. Paint composition.

\begin{tabular}{ccc}
\hline Serial No. & Ingredients & Quantity $(\mathbf{g})$ \\
\hline 1 & Nano mill & 70.60 \\
2 & slurry & 20.00 \\
3 & SAC & 6.00 \\
4 & PG & 2.00 \\
5 & PMS & 0.84 \\
6 & HAT & 0.56 \\
Total & MHD & 100.00 \\
\hline
\end{tabular}

Dirt collection index $\left(D_{\mathrm{c}}\right)$ indicates the tendency of a surface to resist the accumulation of dirt and average dirt resistance. It is calculated by using standard ASTM D 3719-00 [41]. Algae growth percentage is measured using the software Image $1.50 \mathrm{i}$ "Wayne Rasband, National Institute of Health USA".

\subsection{Experimental Observations}

The Temperature $\left({ }^{\circ} \mathrm{C}\right)$ and Humidity $(\%)$ were taken as recorded in Pakistan Meteorological Department (Met) Lahore Pakistan for the months May 2016 to April 2017. The maximum and minimum daily temperature readings were taken to measure the daily average temperature. The daily average temperatures were then used to compute the average temperature per day by dividing their sum with the given number of days. Similarly, the average humidity was also measured. These average values of Temperature and Humidity for the respective number of days were computed and recorded against the given dates of the months as mentioned in Table 3. Paint sample prepared was tested for algae growth. Four concrete slabs were coated with developed paint and conventional paints. Composition of conventional Paints A, B or C cannot be discussed because formulation is a confidential information. Ingredients in paint formulations are proprietary and trade secrets. Paint companies in Pakistan do not disclose their compositions. Conventional Paints A, B or C are top three brands of acrylic latex façade paints available in Pakistan market. Newly developed paint, conventional Paints A, B and C were applied on four cementitious slabs independently and placed in outdoor experimental sight of Brighto Paints Private Limited Pakistan, in grass to facilitate algae growth where appropriate sunlight, dirt and humidity are present. Dimensions of each slab is 17 in. (width) $\times 35$ in. (length) $\times$ 2.25 in. (width) as shown in Figure 1.

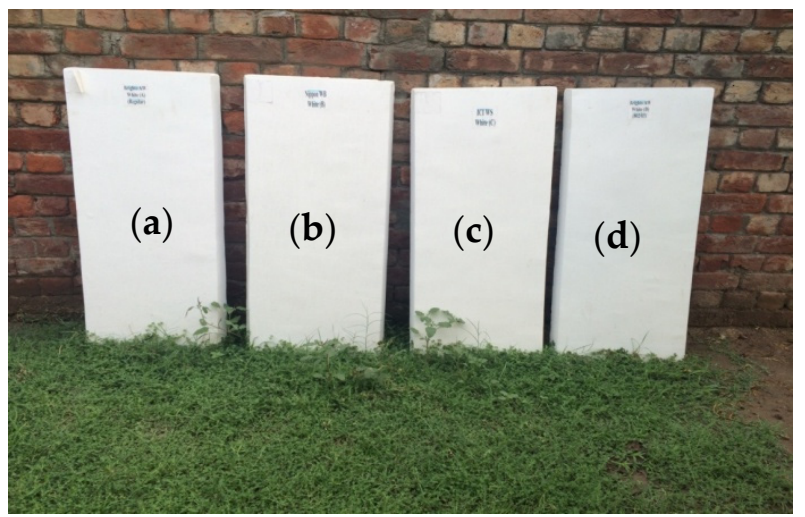

Figure 1. Painted slabs with (a) conventional Paint A, (b) conventional Paint B, (c) conventional Paint C, (d) newly developed paint. 
Table 3. Summary of experimental results of Algal growth.

\begin{tabular}{|c|c|c|c|c|c|c|c|c|c|c|}
\hline \multirow{2}{*}{ Date } & \multirow{2}{*}{$\begin{array}{c}\text { Temperature } \\
\left({ }^{\circ} \mathrm{C}\right)\end{array}$} & \multirow{2}{*}{$\begin{array}{c}\text { Humidity } \\
(\%)\end{array}$} & \multicolumn{2}{|c|}{ Newly Developed Paint } & \multicolumn{2}{|c|}{ Conventional Paint A } & \multicolumn{2}{|c|}{ Conventional Paint B } & \multicolumn{2}{|c|}{ Conventional Paint $\mathrm{C}$} \\
\hline & & & $D_{\mathrm{c}}$ Value & Algae \% & $D_{\mathrm{c}}$ Value & Algae \% & $D_{\mathrm{c}}$ Value & Algae \% & $D_{\mathrm{c}}$ Value & Algae \% \\
\hline $23 / 05 / 2016$ & 32.54 & 47.22 & 100.8 & 0.00 & 98.6 & 0.06 & 99.3 & 0.21 & 100.6 & 0.08 \\
\hline $01 / 06 / 2016$ & 32.96 & 43.33 & 98.7 & 0.05 & 98.7 & 0.75 & 97.7 & 0.46 & 98.1 & 0.58 \\
\hline $11 / 06 / 2016$ & 33.09 & 61.78 & 98.3 & 0.37 & 98.2 & 0.19 & 97 & 0.56 & 97.7 & 0.38 \\
\hline $21 / 06 / 2016$ & 33.14 & 66.44 & 98.66 & 0.08 & 98.24 & 0.68 & 96.48 & 0.04 & 97.7 & 0.54 \\
\hline $01 / 07 / 2016$ & 32.16 & 76.22 & 98.03 & 0.01 & 97.72 & 0.11 & 96.43 & 0.03 & 97.61 & 0.05 \\
\hline $11 / 07 / 2016$ & 30.47 & 79.22 & 98.14 & 0.18 & 98.04 & 0.25 & 96.35 & 0.35 & 97.31 & 0.71 \\
\hline $21 / 07 / 2016$ & 29.44 & 80.6 & 97.85 & 0.17 & 97.31 & 0.93 & 96.49 & 0.20 & 97.03 & 0.28 \\
\hline $01 / 08 / 2016$ & 29.87 & 78 & 97.91 & 0.03 & 97.47 & 0.04 & 96.11 & 1.39 & 97.08 & 0.05 \\
\hline $11 / 08 / 2016$ & 29.78 & 74 & 98.05 & 0.10 & 97.63 & 0.07 & 96.21 & 0.50 & 96.93 & 0.12 \\
\hline $21 / 08 / 2016$ & 30.64 & 84.5 & 97.83 & 4.22 & 97.68 & 1.27 & 96.1 & 0.95 & 96.6 & 2.60 \\
\hline $01 / 09 / 2016$ & 29.79 & 69.25 & 96.88 & 5.17 & 96.8 & 9.55 & 95.64 & 13.19 & 96.33 & 7.08 \\
\hline $10 / 09 / 2016$ & 30.93 & 70.3 & 96.62 & 0.41 & 96.55 & 0.48 & 95.46 & 0.52 & 96.2 & 1.28 \\
\hline $21 / 09 / 2016$ & 31 & 75 & 96.99 & 0.15 & 96.96 & 0.36 & 95.43 & 0.16 & 96.35 & 1.62 \\
\hline $01 / 10 / 2016$ & 28.07 & 70.44 & 96.16 & 0.17 & 96.09 & 0.61 & 94.3 & 0.93 & 95.62 & 0.45 \\
\hline $11 / 10 / 2016$ & 29.59 & 70.44 & 96.1 & 2.40 & 96 & 3.53 & 94.48 & 3.15 & 95.42 & 6.73 \\
\hline $21 / 10 / 2016$ & 25.61 & 76.2 & 96.49 & 1.12 & 96.38 & 2.02 & 94.36 & 1.62 & 95.49 & 0.51 \\
\hline $01 / 11 / 2016$ & 23.09 & 81.22 & 94.61 & 0.45 & 93.55 & 1.95 & 92 & 0.89 & 91.63 & 0.50 \\
\hline $11 / 11 / 2016$ & 20.44 & 73.56 & 95.85 & 0.78 & 95.37 & 2.85 & 93.54 & 6.92 & 94.22 & 1.52 \\
\hline $21 / 11 / 2016$ & 19.67 & 72.11 & 94.87 & 1.06 & 94.64 & 3.84 & 93.02 & 8.98 & 93.7 & 2.58 \\
\hline $01 / 12 / 2016$ & 18.84 & 86 & 94.08 & 0.85 & 93.97 & 0.74 & 92.92 & 0.45 & 93.84 & 1.68 \\
\hline $11 / 12 / 2016$ & 16.92 & 80.78 & 93.96 & 0.20 & 93.86 & 2.81 & 92.79 & 0.22 & 93.77 & 0.21 \\
\hline $21 / 12 / 2016$ & 14.6 & 87 & 93.42 & 0.34 & 93.29 & 0.40 & 91.64 & 0.08 & 92.2 & 0.55 \\
\hline $02 / 01 / 2017$ & 15.12 & 78 & 93.63 & 0.21 & 93.35 & 0.47 & 91.58 & 0.77 & 92.32 & 0.23 \\
\hline $11 / 01 / 2017$ & 14.39 & 84.22 & 93.53 & 0.51 & 93.3 & 0.40 & 91.67 & 0.56 & 92.25 & 0.43 \\
\hline $21 / 01 / 2017$ & 11.46 & 80.21 & 93.46 & 1.53 & 93.13 & 0.39 & 92.28 & 1.81 & 93.04 & 1.34 \\
\hline $21 / 02 / 2017$ & 16.47 & 62.38 & 93 & 0.70 & 92.95 & 0.87 & 91.27 & 9.96 & 91.94 & 0.77 \\
\hline $01 / 03 / 2017$ & 19.21 & 71.7 & 94.37 & 0.32 & 94.17 & 0.32 & 92.21 & 1.55 & 92.38 & 0.98 \\
\hline $11 / 03 / 2017$ & 18.53 & 58.65 & 94.31 & 0.60 & 94.23 & 2.86 & 91.94 & 0.71 & 92.11 & 0.40 \\
\hline $11 / 04 / 2017$ & 24.68 & 47.22 & 91.71 & 1.32 & 90.96 & 1.53 & 90.49 & 1.87 & 90.07 & 1.84 \\
\hline
\end{tabular}


Due to administrative reasons $D_{\mathrm{c}}$ readings and percentage surface area covered by algae was measured for every slab on the dates mentioned in Table 3. $D_{c}$ readings were taken using ASTM D 3719-00 [41].

In order to take $D_{\mathrm{c}}$ readings, Initial Lightness $\left(L^{*} \mathrm{a}\right)$ readings are taken through color Spectrophotometer (BYK Gardner Spectro-Guide Sphere model 6834, BYK-Gardner GmbH, Geretsried, Germany). Final Lightness $\left(L^{*} \mathrm{~b}\right)$ values are taken, on dates mentioned in Table 3, using color Spectrophotometer. Dirt collection index $\left(D_{c}\right)$ is measured according to following formula.

$$
D_{\mathrm{c}}=\left(L^{*} \mathrm{~b} / L^{*} \mathrm{a}\right) \times 100
$$

where $D_{\mathrm{c}}=$ Dirt collection index, $L^{*} \mathrm{a}=$ Lightness reading of fresh panel, $L^{*} \mathrm{~b}=$ Lightness reading of dirt exposed panel.

Tape test was performed on the slabs on the specific dates and the percentage surface area covered by algae was measured for every slab by doing the image analysis of the microscopic pictures of the tapes as shown in Figure 2.

Microscopic Pictures of Tape Test for Observing Algal Growth

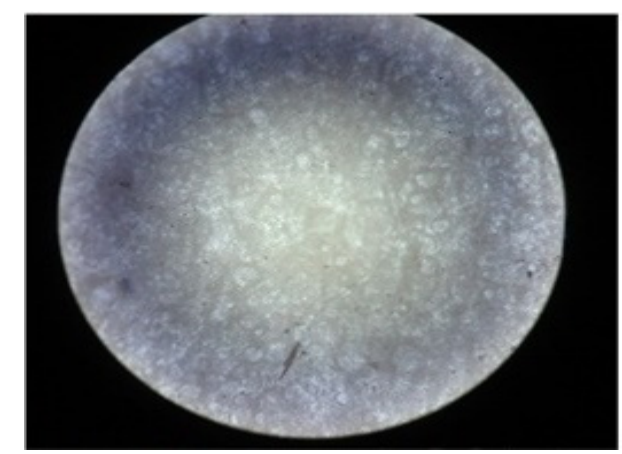

Painted slabs with newly developed paint

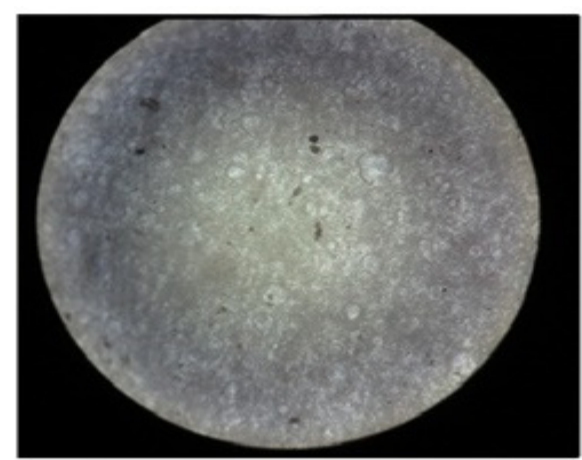

Painted slabs with Paint B

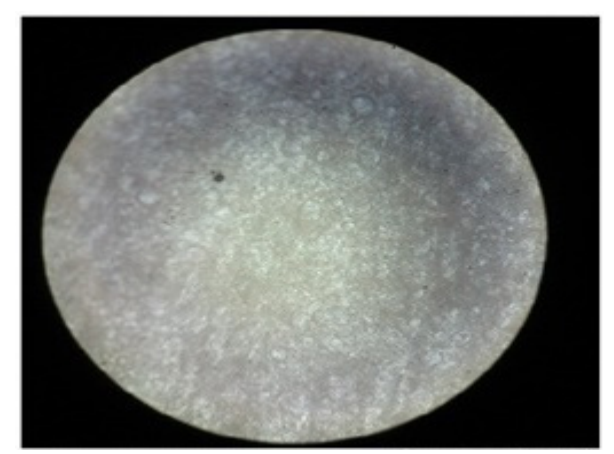

Painted slabs with Paint A

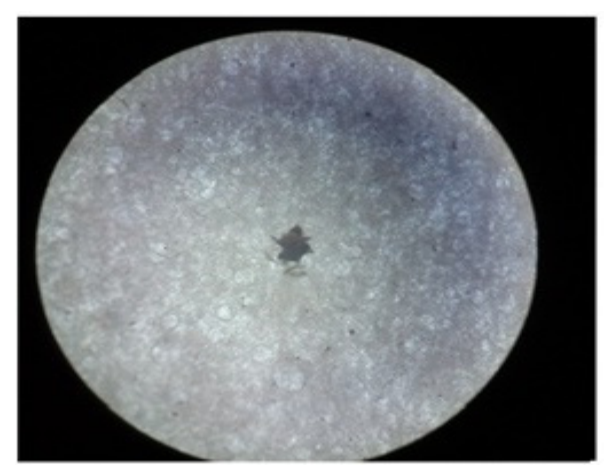

Painted slabs with Paint C

Figure 2. Microscopic pictures of tape Test $(10 \times)$.

The threshold was adjusted to detect the darker spots of algae. The percentage of darker areas was measured using the software ImageJ 1.50i "Wayne Rasband, National Institute of Health USA" [42].

\subsubsection{Anderson Darling's test for Normality}

Anderson Darling's test is used to test the Normality of a variable. A p-value of the statistic less than 0.05 leads to the rejection of the hypothesis of the data to follow the Normal distribution. 


\subsubsection{The Coefficient of Determination}

The Criteria of $R$-square $\left(R^{2}\right)$ is used for to explore the variation in the model explained by the independent variables. It is defined as

$$
R^{2}=1-\frac{\text { SSE }}{\text { TSS }}
$$

where SSE is Error sum of squares and TSS denotes Total sum of squares. For the best model $R^{2}$ value must be large (as close to 1 as possible) [43].

2.3.3. The Adjusted $R$-square $\left(R^{2}\right.$-Adj)

$R^{2}$-Adjis used for judging the goodness of fit and to compare models having different numbers of predictor variables. It is defined as $R^{2}-\mathrm{Adj}=1-\frac{\frac{\mathrm{SSE}}{(n-p-1)}}{\frac{\mathrm{TSS}}{(n-1)}}$. It is the unbiased estimate of population coefficient of determination. It is preferred over coefficient of determination $R^{2}$ as it gives the true change in explained variation due to addition of new explanatory variable [43].

2.3.4. Mallows (1973) $C_{\mathrm{p}}$-values

Mallows (1973) $C_{\mathrm{p}}$-values are the estimated values which are acquired from a fitted regression equation depending on a subset of predictors are usually biased. The mean square error of the estimated value is considered instead of the variance to compare the performance of an equation that is to be considered. The following formula is used to compute the standardized total mean squared error of prediction for the observed data,

$$
J_{p}=\frac{1}{\sigma^{2}} \sum_{i=1}^{n} \operatorname{MSE}\left(\hat{y}_{\mathrm{i}}\right)
$$

where $\operatorname{MSE}\left(\hat{y}_{\mathrm{i}}\right)$ denotes the mean squared error of the ith predicted value from a $p$-term equation, and $\sigma^{2}$ is the random errors variance. To estimate $J_{p}$, Mallows (1973) used the statistic,

$$
C_{p}=\frac{\operatorname{SSE}_{P}}{\hat{\sigma}^{2}}+(2 p-n)
$$

where $\hat{\sigma}^{2}$ is an estimated value of $\sigma^{2}$ and which is obtained from the linear model with the full set of $q$ variables. The expected value of $C_{p}$, is $p$ under the assumption of no bias in the fitted model containing $p$ terms. Hence, the deviation of $C_{\mathrm{p}}$, from $p$ can be taken as a measure of bias. The $C_{\mathrm{p}}$, statistic therefore is a measure of the performance of the predictors transformed in standardized total mean square error of prediction for the observed data values without considering the actual model which is unknown. It includes both the components including bias and the variance. The subsets of predictors that give the minimum values of $C_{p}$, are taken as the anticipated subsets [43].

\subsubsection{The Standard Error of Regression}

The Standard Error of Regression or RMSE is given by

$$
S_{e}=\sqrt{\mathrm{MSE}}=\sqrt{\frac{\mathrm{SSE}}{n-p-1}}
$$

For the best suitable model, the Standard Error of Regression must be the smallest possible [43]. 


\subsubsection{Akaike Information Criteria (AIC)}

The formula for AIC when there is a $p$-term regression model, with a constant and $(p-1)$ variables, is given by

$$
\begin{gathered}
\mathrm{AIC}=n \times \ln \left(\hat{\sigma}^{2}\right)+2 p \\
\hat{\sigma}^{2}=\frac{\mathrm{SSE}}{n}
\end{gathered}
$$

Two regression models for which AIC is not different by 2 are considered as equally suitable. If there are large difference in the values of AIC it would indicate that there is significant dissimilarity between the qualities of the two models. The model with the value of AIC to be minimum is considered as the finest [43].

\subsubsection{The Model}

We use Linear Regression Model of order three to achieve the given objectives of the research including second and third order interactions. The expression of full model is given as below:

$$
\begin{aligned}
& \mathrm{ALGr}=\mathrm{Y}=\beta_{0}+\beta_{1}(\mathrm{NDP})+\beta_{2}(\mathrm{CN}-1)+\beta_{3}(\mathrm{CN}-2)+\beta_{4}(\mathrm{Dys})+\beta_{5}(\mathrm{Hm})+\beta_{6}(\mathrm{Tmp})+ \\
& \beta_{7}(\text { Drt })+\beta_{8}\left(\text { Dys }^{2}\right)+\beta_{9}\left(\mathrm{Hm}^{2}\right)+\beta_{10}\left(\mathrm{Tmp}^{2}\right)+\beta_{11}\left(\mathrm{Drt}^{2}\right)+\beta_{12}\left(\mathrm{Hm}^{*} \mathrm{Tmp}\right)+\beta_{13}\left(\mathrm{Hm}^{*} \mathrm{Drt}\right) \\
& +\beta_{14}\left(\mathrm{Tmp} \mathrm{p}^{*} \mathrm{Drt}\right)+\beta_{15}\left(\mathrm{Dys}^{3}\right)+\beta_{16}\left(\mathrm{Hm}^{3}\right)+\beta_{17}\left(\mathrm{Tmp}^{3}\right)+\beta_{18}\left(\mathrm{Hm}^{2 *} \mathrm{Drt}\right)+\beta_{19}(\mathrm{NoD} \text { Drt })+ \\
& \beta_{20}\left(\mathrm{NoD}^{*} \mathrm{Hm}\right)+\beta_{21}\left(\mathrm{Dys}^{*} \mathrm{Tmp}\right)+\beta_{22}\left(\mathrm{Dys}^{*} \mathrm{Hm}^{2}\right)+\beta_{23}\left(\mathrm{Hm}^{3}\right)+\beta_{24}\left(\mathrm{Tmp}^{3}\right)+\beta_{18}\left(\mathrm{Drt}^{3}\right)+ \\
& \beta_{25}\left(\text { Dys }^{2 *} \mathrm{Hm}\right)+\beta_{26}\left(\text { Dys }^{2 *} \mathrm{Tmp}\right)+\beta_{27}\left(\mathrm{Dys}^{2 *} \mathrm{Drt}\right)+\beta_{28}\left(\mathrm{Dys}^{2 *} \mathrm{Tmp}\right)+\beta_{29}\left(\mathrm{Dys}^{2 *} \mathrm{Drt}\right)+ \\
& \beta_{30}\left(\text { Dys }^{*} \mathrm{Hm}^{*} \mathrm{Tmp}\right)+\beta_{31}\left(\text { Dys }^{*} \mathrm{Hm}^{*} \mathrm{Drt}\right)+\beta_{32}\left(\text { Dys }^{*} \mathrm{Tmp}{ }^{*} \mathrm{Drt}\right)+\beta_{33}\left(\mathrm{Dys}^{*} \mathrm{Drt}^{2}\right)+ \\
& \beta_{34}\left(\mathrm{Hm}^{2 *} \mathrm{Tmp}\right)+\beta_{35}\left(\mathrm{Hm}^{2 *} \mathrm{Drt}\right)+\beta_{36}\left(\mathrm{Hm}^{*} \mathrm{Tmp}^{2}\right)+\beta_{37}\left(\mathrm{Hm}^{*} \mathrm{Tmp}{ }^{*} \mathrm{Drt}\right)+ \\
& \beta_{38}\left(\mathrm{Hm}^{*} \mathrm{Drt}^{2}\right)+\beta_{39}\left(\mathrm{Tmp}^{2 *} \mathrm{Drt}\right)+\beta_{40}\left(\mathrm{Tmp}^{*} \mathrm{Drt}^{2}\right)+\epsilon
\end{aligned}
$$

where ALGr $=$ Algae Surface Area in pixel $/ \mathrm{mm} ;$ Drt $=$ Dirt Collection Index, $D_{c} ;$ Dys $=$ Number of days; $\mathrm{Tmp}=$ Temperature,${ }^{\circ} \mathrm{C} ; \mathrm{Hm}=$ Humidity, $\%$; NDP $=1$, Dummy variable for Newly developed paint, $=0$, other paint; $\mathrm{CN}-1=1$, Dummy variable for conventional Paint $\mathrm{A},=0$, other paint; $\mathrm{CN}-2=1$, Dummy variable for Conventional Paint $\mathrm{B},=0$, other paint and $\epsilon$ denotes the error term consisting of unexplained variation in the dependent variable, the Algae growth rate.

The regression coefficients for each of the variables up to order three and along with their respective interactions are denoted by $\beta_{1}, \beta_{2}, \cdots, \beta_{40}$. Each of the given regression coefficients give the average rate of change in Algae growth rate due to a unit value change in the respective variable. $\beta_{0}$ denotes the intercept in the model. For each candidate model corresponding to the respective paint type there will be different value of $\beta_{0}$, which represents the average Algae growth rate when the given paint is to be used after eliminating the effects of all other variables.

The data are analyzed using MINITAB version-17. The Stepwise method is used to achieve the final model.

\section{Results, Analysis and Discussion}

The distribution of response variable (Algae Area \%) before commencing the regression analysis from Table 4 and the Histogram given in Figure 3 was found to be positively skewed.

Table 4. Statistics of Algae Area.

\begin{tabular}{cccc}
\hline Mean & Standard Deviation & Anderson Darling Statistic Value & $p$-Value \\
\hline 1.37 & 2.207 & 16.073 & $<0.005$ \\
\hline
\end{tabular}




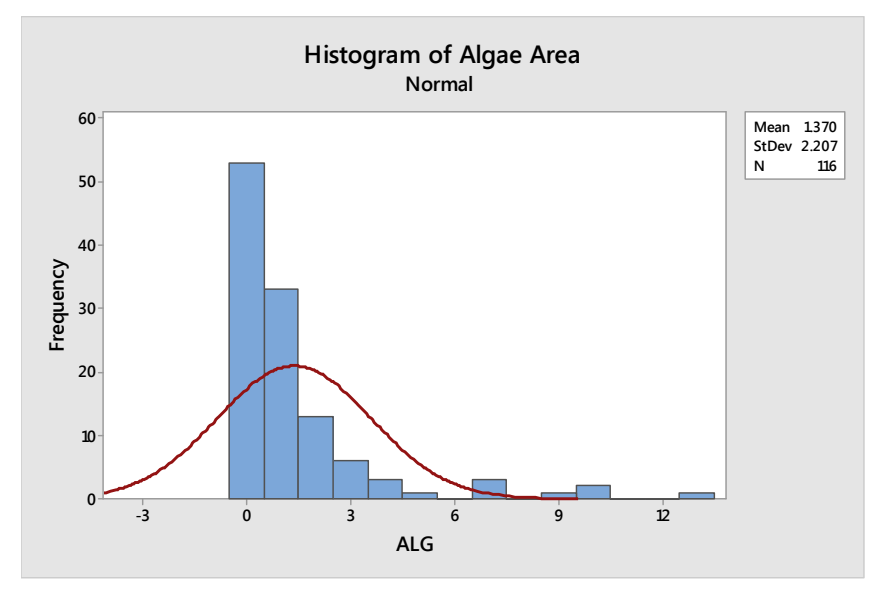

Figure 3. Histogram of Algae Area.

Anderson Darling's test for Normality showed a $p$-value less than 0.05. The Logarithmic transformation was used to make the distribution of the response variable Normal. The transformed variable is named as new Algae Area and results of transformed variable is given in Table 5 and Figure 4a,b. Anderson Darling's test for Normality showed a $p$-value greater than 0.05 leading to the acceptance of the hypothesis of the data to follow the Normal distribution and from Figure 4a,b.

Table 5. Statistics of new Algae Area.

\begin{tabular}{cccc}
\hline Mean & Standard Deviation & Anderson Darling Statistic Value & $p$-Value \\
\hline-0.27 & 0.6928 & 1.0838 & 0.01 \\
\hline
\end{tabular}

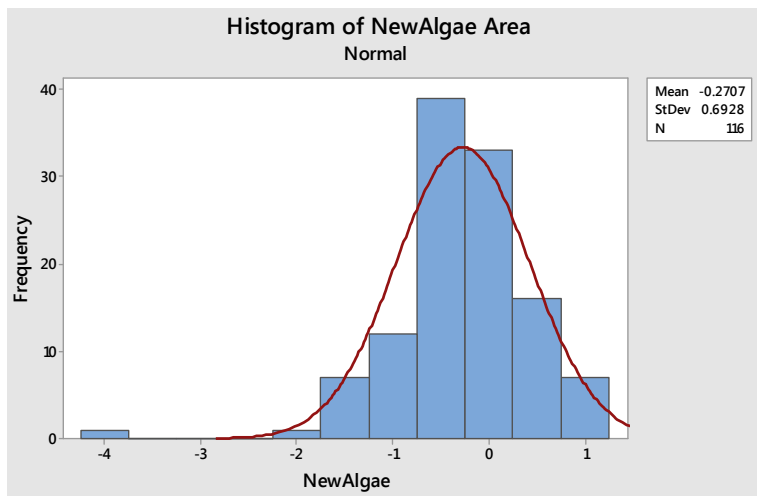

(a)

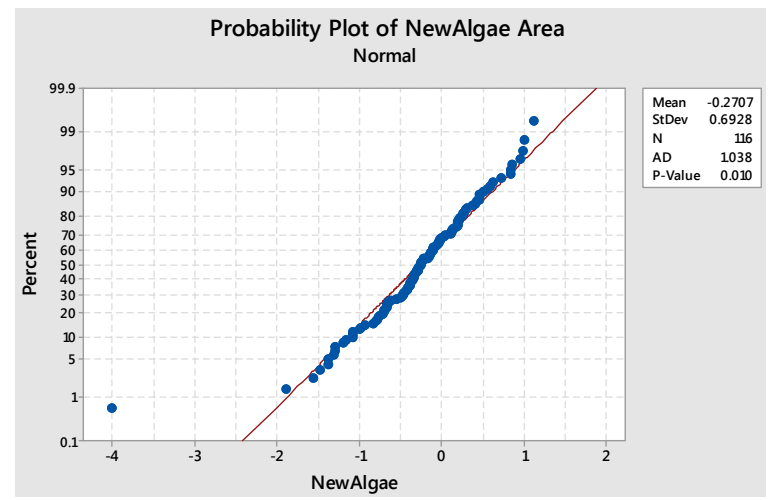

(b)

Figure 4. (a) Histogram of new Algae area. (b) Probability plot of new Algae area.

The Stepwise selection procedure applied on full regression model yielded the results of the final model to be selected either from Steps 15, 16 or 17, as given in Table 6. The results of $R$-square, Adjusted $R$-square, Mallows $C_{\mathrm{p}}$, Standard error of regression and AIC were used for choosing the best suitable model as shown in Table 7. Minitab was instructed to include dummy variables at each step as the purpose of study was to predict the Average Algae growth rate on the basis of models for each of the competitive paint type. Table 8 gives the ANOVA for the final model and the expressions of fitted regression equations are also given below. 
The Regression equation for NDP is given by:

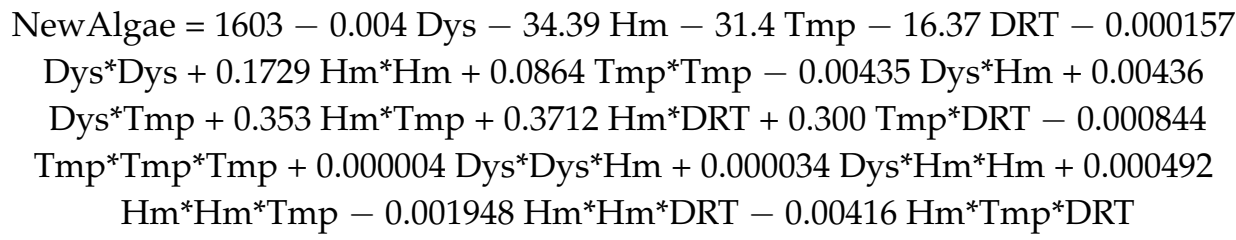

With the help of Equation (9), algae growth could be predicted for given values of the independent variables. For example, if number of days are 40 , humidity $45 \%$, temperature $30{ }^{\circ} \mathrm{C}$ and dirt resistance 98, then Algae growth \% age will be:

New Algae $=-2.7997$

Algae growth $=$ anti $\log (-2.7997)=0.002 \%$

Table 6. Step wise selection procedure results.

\begin{tabular}{ccccccc}
\hline \multirow{2}{*}{$\begin{array}{c}\text { Regression } \\
\text { Variables }\end{array}$} & \multicolumn{2}{c}{ Step 15 } & \multicolumn{2}{c}{ Step 16 } & \multicolumn{2}{c}{ Step 17 } \\
\cline { 2 - 7 } & Coefficients & $p$-Value & Coefficients & $p$-Value & Coefficients & $p$-Value \\
\hline Constant & 1203 & - & 1234 & - & 1603 & - \\
NDP & -0.526 & 0.001 & -0.53 & 0.001 & -0.529 & 0.001 \\
CN-1 & -0.157 & 0.282 & -0.159 & 0.271 & -0.159 & 0.269 \\
CN-2 & 0.179 & 0.228 & 0.178 & 0.227 & 0.186 & 0.205 \\
Dys & 0.053 & 0.788 & -0.003 & 0.981 & -0.004 & 0.966 \\
Hm & -27.53 & 0.001 & -27.04 & 0.001 & -34.39 & 0.001 \\
Tmp & -20.7 & 0.047 & -22.4 & 0.014 & -31.4 & 0.005 \\
Dys*Hm & -0.00338 & 0.232 & -0.00369 & 0.166 & -0.00435 & 0.107 \\
Dys*Tmp & 0.00257 & 0.035 & 0.00277 & 0.009 & 0.00436 & 0.005 \\
Hm*Tmp & 0.22 & 0.079 & 0.232 & 0.054 & 0.353 & 0.017 \\
Dys*Hm*Tmp & - & - & - & - & - & - \\
Tmp*Tmp & 0.0787 & 0.004 & 0.0814 & 0.002 & 0.0864 & 0.001 \\
DRT & -12.67 & 0.002 & -12.98 & 0.001 & -16.37 & 0 \\
Tmp*Drt & 0.205 & 0.047 & 0.2214 & 0.014 & 0.3 & 0.005 \\
Tmp*Tmp*DRT & - & - & - & - & - & - \\
Hm*DRT & 0.3074 & 0 & 0.3025 & 0 & 0.3712 & 0 \\
Hm*Hm & 0.1455 & 0.004 & 0.1386 & 0.002 & 0.1729 & 0.001 \\
Dys*Hm*Hm & 0.000033 & 0.123 & 0.000036 & 0.074 & 0.000034 & 0.092 \\
Hm*Hm*Tmp & 0.000596 & 0.007 & 0.000592 & 0.007 & 0.000492 & 0.032 \\
Hm*Hm*DRT & -0.001708 & 0.001 & -0.001639 & 0 & -0.001948 & 0 \\
Tmp*Tmp*Tmp & -0.000866 & 0.036 & -0.000907 & 0.021 & -0.000844 & 0.032 \\
Dys*Dys & 0.000047 & 0.417 & 0.000061 & 0.115 & -0.000157 & 0.317 \\
Dys*DRT & -0.00058 & 0.741 & - & - & - & - \\
Dys*Dys*DRT & - & - & - & - & - & - \\
Hm*Tmp*DRT & -0.00299 & 0.016 & -0.0031 & 0.009 & -0.00416 & 0.003 \\
Dys*Dys*Hm & - & - & - & - & 0.000004 & 0.154 \\
\hline
\end{tabular}

Table 7. Step wise selection procedure results (contd.).

\begin{tabular}{ccccc}
\hline $\begin{array}{c}\text { Model Selection } \\
\text { Criteria }\end{array}$ & Step 15 & Statistics & Step 16 & Step 17 \\
\hline Standard Error & 0.491774 & & 0.489465 & 0.486741 \\
$R$-sq & $58.81 \%$ & & $58.77 \%$ & $59.65 \%$ \\
$R$-sq(adj) & $49.61 \%$ & - & $50.09 \%$ & $50.64 \%$ \\
$R$-sq(pred) & $31.55 \%$ & & $32.80 \%$ & $32.83 \%$ \\
Mallows' $C_{\mathrm{p}}$ & 23.21 & & 21.32 & 21.27 \\
\hline
\end{tabular}


Table 8. ANOVA.

\begin{tabular}{cccccccc}
\hline Source & $\begin{array}{c}\text { Degree of } \\
\text { Freedom }\end{array}$ & Seq SS & Contribution & Adj SS & Adj MS F & $p$-Value & Value \\
\hline Regression & 21 & 32.9269 & $59.65 \%$ & 32.9269 & 1.56795 & 6.62 & 0 \\
Dys & 1 & 8.7024 & $15.77 \%$ & 0.0004 & 0.00043 & 0 & 0.966 \\
Hm & 1 & 1.5116 & $2.74 \%$ & 3.0528 & 3.05282 & 12.89 & 0.001 \\
Tmp & 1 & 2.7377 & $4.96 \%$ & 1.9725 & 1.97249 & 8.33 & 0.005 \\
DRT & 1 & 1.3884 & $2.52 \%$ & 3.0968 & 3.09679 & 13.07 & 0 \\
NDP & 1 & 1.9468 & $3.53 \%$ & 2.7067 & 2.70665 & 11.42 & 0.001 \\
CN-1 & 1 & 0.0368 & $0.07 \%$ & 0.2928 & 0.29277 & 1.24 & 0.269 \\
CN-2 & 1 & 0.0162 & $0.03 \%$ & 0.3854 & 0.38536 & 1.63 & 0.205 \\
Dys*Dys & 1 & 3.2059 & $5.81 \%$ & 0.2393 & 0.23929 & 1.01 & 0.317 \\
Hm*Hm & 1 & 0.1791 & $0.32 \%$ & 2.8798 & 2.87981 & 12.16 & 0.001 \\
Tmp*Tmp & 1 & 0.001 & $0.00 \%$ & 2.6893 & 2.68929 & 11.35 & 0.001 \\
Dys*Hm & 1 & 0.059 & $0.11 \%$ & 0.6287 & 0.62871 & 2.65 & 0.107 \\
Dys*Tmp & 1 & 0.0243 & $0.04 \%$ & 1.9548 & 1.95478 & 8.25 & 0.005 \\
Hm*Tmp & 1 & 0.1876 & $0.34 \%$ & 1.3982 & 1.39818 & 5.9 & 0.017 \\
Hm*DRT & 1 & 5.0513 & $9.15 \%$ & 3.6732 & 3.67321 & 15.5 & 0 \\
Tmp*DRT & 1 & 0.0538 & $0.10 \%$ & 1.987 & 1.98701 & 8.39 & 0.005 \\
Tmp*Tmp*Tmp & 1 & 0.0005 & $0.00 \%$ & 1.12 & 1.12393 & 4.74 & 0.032 \\
Dys*Dys*Hm & 1 & 0.0861 & $0.16 \%$ & 0.4896 & 0.48958 & 2.07 & 0.154 \\
Dys*Hm*Hm & 1 & 1.5526 & $2.81 \%$ & 0.6873 & 0.68735 & 2.9 & 0.092 \\
Hm*Hm*Tmp & 1 & 2.2998 & $4.17 \%$ & 1.1293 & 1.12934 & 4.77 & 0.032 \\
Hm*Hm*DRT & 1 & 1.7178 & $3.11 \%$ & 3.8722 & 3.87216 & 16.34 & 0 \\
Hm*Tmp*DRT & 1 & 2.168 & $3.93 \%$ & 2.168 & 2.16796 & 9.15 & 0.003 \\
Error & 94 & 22.2701 & $40.35 \%$ & 22.2701 & 0.23692 & - & - \\
Total & 115 & 55.1971 & $100.00 \%$ & - & - & - & - \\
\hline
\end{tabular}

Tools to Test the Validity of the Model: Assumptions of the Model

The assumptions of the regression model designate that how well the model describes the true relationship between the dependent variable and the independent variables and make it possible for us to develop measures of reliability for the estimators of regression coefficients. These include independence of errors (residuals), Normality of errors and a constant variance for the distributions of errors [44]. The model seems to satisfy these assumptions; the structure less plot of residual over time Figure 5, and the value of Durbin-Watson Statistic $=1.97714$ indicates that the errors independently distributed. Refer to Figures 6 and 7 and the $p$-value of Anderson Darling test statistic which is 0.724, indicate that the errors are normally distributed. Refer to Figure 8 , the structure less plot of residuals over fitted values verifies the assumption of constant variance.

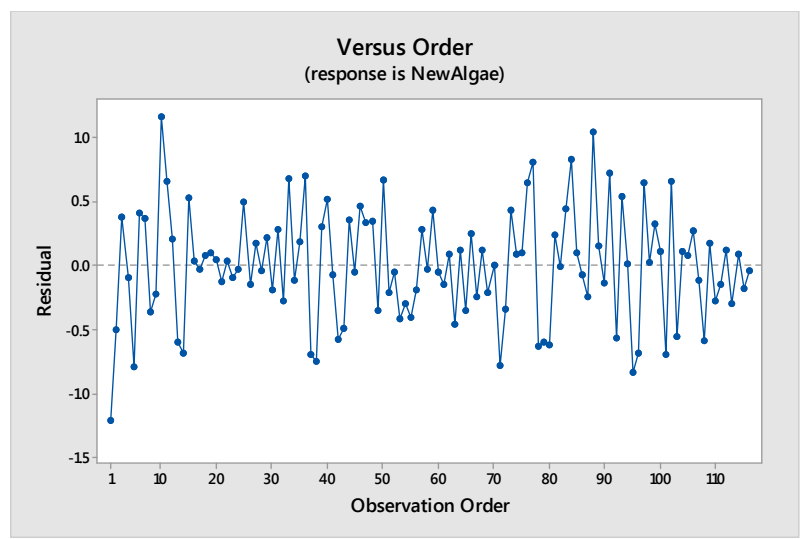

Figure 5. Residuals versus observation order. 


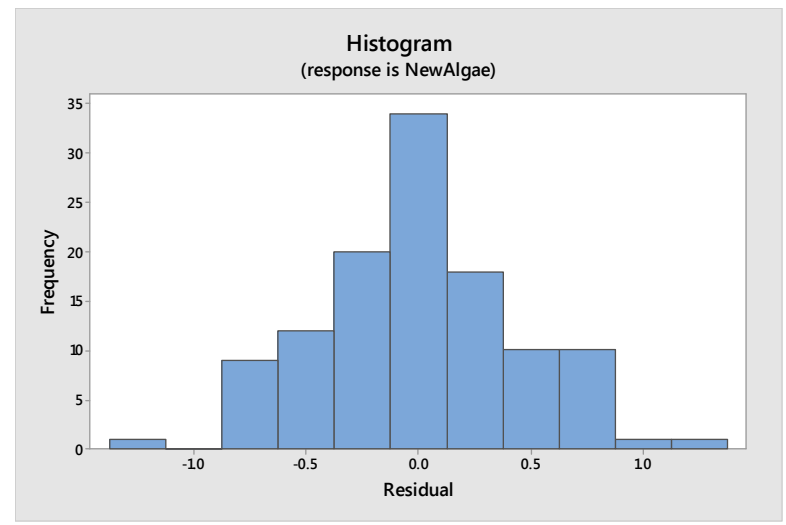

Figure 6. Histogram of residuals.

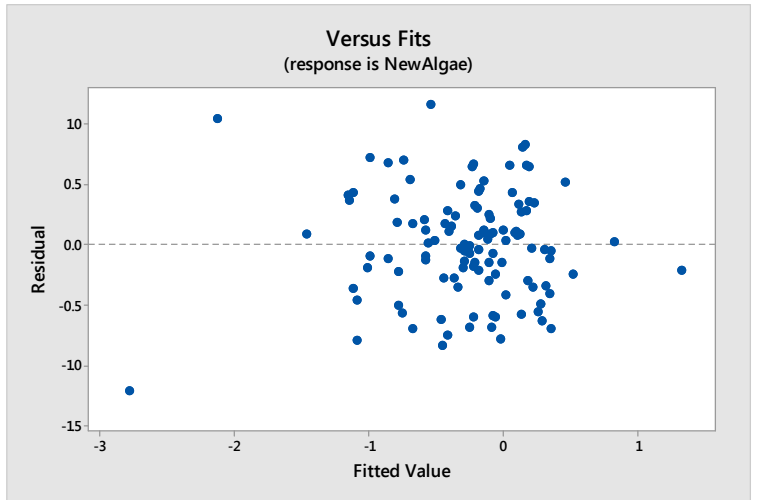

Figure 7. Normal probability plot.

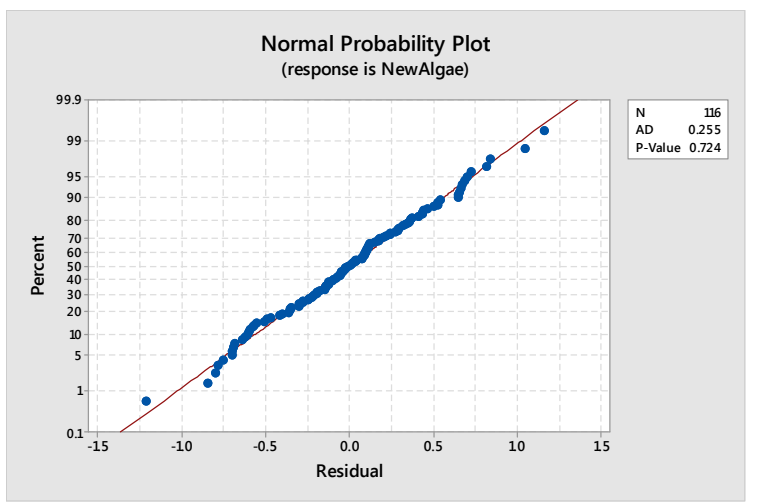

Figure 8. Residual versus fitted values.

Keeping the effect of all other factors constant, the use of newly developed paint significantly decreases the average algae growth rate by $0.53 \%$. The variation in algae growth explained by this variable is $3.53 \%$; if humidity increases by one percent, algae growth will decrease by $27.04 \%$. The variation in algae growth explained by the humidity variable is $2.74 \%$; if temperature increases by one degree centigrade, algae growth will decrease by $22.4 \%$. The variation in algae growth explained by the temperature variable is $4.96 \%$; if dirt resistance of a paint increases by one percent, algae growth will decrease by $12.98 \%$. The variation in algae growth explained by the dirt resistance variable is $2.52 \%$; if there is a positive unit change in the joint effect of time and temperature, it would result in increase in algae growth by $0.0027 \%$. The variation in algae growth explained by the joint effect of these variable is $0.04 \%$; if there is a positive unit change in the joint effect of humidity and temperature it would result in an increase in algae growth by $0.232 \%$. The variation in algae growth explained by the joint effect 
of these variables is $0.34 \%$; if there is a positive unit change in the joint effect of dirt resistance and temperature it would result in an increase in algae growth by $0.2214 \%$. The variation in algae growth explained by the joint effect of these variable is $0.10 \%$; if there is a positive unit change in the joint effect of dirt resistance and humidity, algae growth will increase by $0.3025 \mathrm{pixel} / \mathrm{mm}$. The variation in algae growth explained by the joint effect of these variables is $9.15 \%$; if there is an increase in the quadratic effect of humidity, algae growth will increase by $0.1386 \mathrm{pixel} / \mathrm{mm}$. The variation in algae growth explained by this quadratic effect is $0.32 \%$; if there is a positive unit change in the joint linear effect of time and quadratic effect of humidity, algae growth will increase by $0.000036 \mathrm{pixel} / \mathrm{mm}$. The variation in algae growth explained by this interaction effect is $0.16 \%$; if there is a positive unit change in the joint linear effect of temperature and quadratic effect of humidity, algae growth will increase by $0.000592 \mathrm{pixel} / \mathrm{mm}$. The variation in algae growth explained by this interaction effect is $4.17 \%$; if there is a positive unit change in the joint of dirt resistance and quadratic effect of humidity, algae growth will decrease by $0.001639 \mathrm{pixel} / \mathrm{mm}$. The variation in algae growth explained by this interaction effect is $3.11 \%$; if there is a positive unit change in the joint linear effect of dirt resistance, temperature and humidity, algae growth will decrease by $0.0031 \mathrm{pixel} / \mathrm{mm}$. The variation in algae growth explained by this interaction effect of the three variables is $3.93 \%$; the cubic effect of temperature variable by one degree centigrade, will result in decrease of algae growth by $0.000907 \%$.

The individual effect of Time (number of days) came out to be insignificant, though its contribution towards the algae growth was $15.77 \%$. However, when time is incorporated with temperature, it had significant effect on algae growth rate. Similarly, when time variable is mixed with the quadratic effect of humidity variable it significantly affected the algae growth rate. The competitor paints 1,2 and 3 were found to be insignificantly affecting the algae growth rate. However, the newly developed paint had a significant effect on the reduction on average algae growth rate. The individual effect of humidity variable was inversely related with average algae growth while the combination of humidity and temperature, humidity and dirt resistance, humidity and time, and the quadratic effect of humidity were found to increase the average algae growth rate.

\section{Conclusions}

On the basis of discussions of preceding section, the fitted regression Equation (9) can be considered as the best suitable model. It is concluded from results of Equation (10) that expected average algae growth is $0.002 \%$ when number of days are 40 , humidity $45 \%$, temperature $30{ }^{\circ} \mathrm{C}$, and dirt resistance 98. Similarly, we can predict other values of average algae growth for given values of independent variables. In this study, algae-resistant paint is developed without using any algaecides. Algaecides are hazardous chemicals for mankind and other organisms. New processes are used to produce the paint which involves Nano mill to get a finer surface area of pigments. The new paint is environmentally friendly.

The expected average algae growth rate for newly developed paint is the lowest with a significant value of $0.53 \% \mathrm{pixel} / \mathrm{mm}$, as compared to the competitor paints. Among all competitor paints, newly developed may be considered as the most suitable paint with respect to its algae resistant property.

Keeping the effect of all other factors constant, if a given paint is exposed twice to a fixed $1 \%$ incremented humidity level, the expected algae growth will increase by $0.1386 \% \times 2=0.2772 \%$ $\mathrm{pixel} / \mathrm{mm}$, with a $0.32 \%$ of the total explained variation in algae growth is due to this dual impact. Therefore, it could be inferred that the impact of humidity level on the expected algae growth is observed to be significantly positive when the paint is exposed twice to the same humidity level; if the paint is exposed once to a given incremented one-degree Celsius temperature, there is expected decrease in algae growth by $31.4 \%$ pixel $/ \mathrm{mm}$. $4.96 \%$ variation in the algae growth is explained by the linear effect of temperature; If the given paint is exposed twice to a given temperature the expected increase in algae growth per one-degree positive increment in temperature will be $0.0864 \% \times 2=$ $0.1728 \%$ pixel $/ \mathrm{mm}$; However, $0.00 \%$ variation in the algae growth is explained by the quadratic effect 
of temperature. If the given paint is exposed thrice to a given temperature the expected decrease in algae growth per one-degree positive increment in temperature will be $0.00084 \%$ pixel $/ \mathrm{mm}$. However, $0.00 \%$ variation in the algae growth is explained by the cubic effect of temperature. The linear effect of temperature on algae growth contributes $4.96 \%$ of the total explained variation hence one may conclude that the exposure of a given paint to a given one degree incremented temperature results in a significant decrease in algae growth; if dirt resistance of a given paint increases by one percent, the expected algae growth will significantly decrease by $16.37 \%$. The $2.62 \%$ variation in the algae growth is explained by the linear effect of dirt resistance. A paint with high dirt resistance property is also expected to be significantly algae resistant; the expected algae growth will significantly increase by $0.00436 \%$ due combine positive unitary effect of time and temperature. The joint impact of time and temperature significantly decrease the algae resistance of a given paint; the expected algae growth will significantly increase by $0.353 \%$ due combine positive unitary effect of humidity and temperature. Keeping the effect of all other factors constant, a given paint, when exposed simultaneously to a given humidity level twice and temperature once, will have a significant positive expected algae growth by $0.00049 \% \mathrm{pixel} / \mathrm{mm}$. The joint impact of humidity level and temperature significantly decrease the algae resistance of a given paint; a paint with a specific dirt resistance when exposed to a given temperature once will have a significant positive expected algae growth by $0.30 \%$ pixel $/ \mathrm{mm}$, with an explained contribution of $0.10 \%$ to this change. The percentage explained contribution of the joint effect of dirt resistance property and temperature is very small and may be ignored; a paint with a specific dirt resistance property when exposed to a given humidity level once, will have a significant positive expected algae growth by $0.3712 \%$ pixel $/ \mathrm{mm}$, with an explained contribution of $9.15 \%$ to this change. The joint impact of dirt resistance property and humidity level significantly decrease the algae resistance of a given paint; a paint with a specific dirt resistance when exposed to a given temperature and humidity level once will have a significant negative expected algae growth by $0.0042 \% \mathrm{pixel} / \mathrm{mm}$, with a significant explained contribution of $3.93 \%$ to this change. The combine effect of dirt resistance property, temperature and humidity level is expected to increase the algae resistance of a paint.

\section{Future Work}

The present study was conducted for a period of one year, however, it could be extended to two or more years to further validate the results. The determination of types of algae could also be an extension of this work. The amount of rain was also not recorded during the experimental period which could be an important parameter to research in future studies. The strength and color of the paint applied on panels (durability factor) after certain period of time could also be studied while making comparisons among paints from different manufacturers.

Author Contributions: Conceptualization, S.A.Q.; Methodology, S.A.Q., A.S. and A.I.; Software, S.A.Q. and M.M.B.; Validation, S.A.Q. and M.M.B.; Formal Analysis, S.A.Q. and M.M.B.; Investigation, S.A.Q. and M.M.B.; Resources, S.A.Q. and M.M.B.; Data Curation, S.A.Q. and M.M.B.; Writing-Original Draft Preparation, S.A.Q., A.S. and A.I.; Writing-Review \& Editing, S.A.Q., A.S., A.I. and M.M.B.; Visualization, S.A.Q. and M.M.B.; Supervision, A.S., A.I. and M.M.B.; Project Administration, S.A.Q., A.S., A.I. and M.M.B.

Funding: This research received no external funding.

Acknowledgments: The support from Brighto Paints Private Limited Pakistan to conduct this research work is gratefully acknowledged.

Conflicts of Interest: The authors declare no conflict of interest.

\section{Acronyms}

ROW Reverse Osmosis Treated Water

DIS Dispex A-40, Dispersant, solution of an ammonium salt of an acrylic polymer in water

MS Magnesium Silicate

HAT Acrysol TT 615, Hydrophobically Modified Anionic Thickener

ZO Zinc oxide 


$\begin{array}{ll}\text { ATD } & \text { KA-100, Anatase Titanium Dioxide } \\ \text { RTD } & \mathrm{TiO}_{2} \text { 2310, Rutile Titanium Dioxide } \\ \text { PG } & \text { Propylene Glycol } \\ \text { PMS } & \text { Wacker 1306, Emulsion of a Polysiloxane Modified with functional Silicone Resin } \\ \text { MHD } & \text { DisplairCF-245, Mineral Hydrocarbons Defoamer } \\ \text { AMP } & \text { AMP-95, 95\%, 2-Amino-2-Methyl-1-Propanol Solution } \\ \text { SAC } & \text { PST-50A, Styrene Acrylic Copolymer Emulsion }\end{array}$

\section{References}

1. Morgans, W.M. Outlines of Paint Technology, 3rd ed.; Griffin: London, UK, 1990.

2. Gaylarde, C.C.; Morton, L.G. Deteriogenic biofilms on buildings and their control. Biofouling 1999, 14, 59-74. [CrossRef]

3. Lakna. Difference between Algae and Fungi. Available online: http://pediaa.com/difference-betweenalgae-and-fungi (accessed on 26 November 2018).

4. Barsanti, L.; Gualtieri, P. Algae: Anatomy, Biochemistry, and Biotechnology, 2nd ed.; CRC Press: Boca Raton, FL, USA, 2006.

5. Leavitt, P.R.; Findlay, D.L.; Hall, R.I.; Smol, J.P. Algal responses to dissolved organic carbon loss and pH decline during whole-lake acidification: Evidence from paleolimnology. Limnol. Oceanogr. 1999, 44, 757-773. [CrossRef]

6. Pendersen, M.F.; Hensen, P.J. Effects of high $\mathrm{pH}$ on the growth and survival of six marine heterotrophic protests. Mar. Ecol. Prog. Ser. 2003, 260, 33-41. [CrossRef]

7. Nakajima, M.; Hokoi, S.; Ogura, D.; Iba, C. Relationship between environmental conditions and algal growth on the exterior walls of the ninna-ji temple, Kyoto. Energy Procedia 2015, 78, 1329-1334. [CrossRef]

8. Banov, A. Paints and Coatings Handbook for Contractors, Architects, and Builders, 2nd ed.; Structures Publishing Company: Farmington, MI, USA, 1973.

9. Falconer, I.R. Potential impact on human health of toxic cyanobacteria. Phycologia 1996, 35, 6-11. [CrossRef]

10. Chorus, I.; Bartram, J. Toxic Cyanobacteria in Water: A Guide to the Public Health Consequences, Monitoring and Management, 1st ed.; CRC Press: London, UK, 1999.

11. Yebra, D.M.; Kill, S.; Darn-Johansen, K. Antifouling technology-Past, present and future steps towards efficient and environmentally friendly antifouling coatings. Prog. Org. Coat. 2004, 50, 75-104. [CrossRef]

12. Bruno, D.W.; Ellis, A.E. Histopathological effects in Atlantic salmon, Salmo salar L., attributed to the use of tributyltin antifoulant. Aquacullure 1988, 72, 15-20. [CrossRef]

13. Lee, H.B.; Lim, L.C.; Cheong, L. Observations on the use of antifouling paint in netcage fish farming in Singapore. Singap. J. Prim. Ind. 1985, 13, 1-12.

14. Konstantinou, I.K. Antifouling Paint Biocides; Springer: Heidelberg, Germany, 2006.

15. Giacomazzi, S.; Cochet, N. Environmental impact of diuron transformation: A review. Chemsophere 2004, 56, 1021-1032. [CrossRef] [PubMed]

16. Diuron Mutagenicity Data; US Environmental Protection Agency (USEPA): Washington, DC, USA, 1986.

17. Sorensen, S.R.; Albers, C.N.; Aamand, J. Rapid mineralization of the phenylurea herbicide diuron by Variovorax sp. strain SRS16 in pure culture and within a two-member consortium. Appl. Environ. Microbiol. 2008, 74, 2332-2340. [CrossRef] [PubMed]

18. Wang, Z.; Wang, Y.; Gong, F.; Zhang, J.; Hong, Q.; Li, S. Biodegradation of carbendazim by a novel actinobacterium Rhodococcusjialingiae djl-6-2. Chemosphere 2010, 81, 639-644. [CrossRef] [PubMed]

19. Amanullah, M.; Hari, B.Y. Evaluation of carbamate insecticides as chemotherapeutic agents for cancer. Indian J. Cancer 2011, 48, 74-79. [CrossRef] [PubMed]

20. Guthery, E.; Seal, L.A.; Anderson, E.L. Zinc pyrithione in alcohol based products for skin antisepsis: Persistence of antimicrobial effects. Am J. Infect. Control 2005, 33, 15-22. [CrossRef] [PubMed]

21. Cooney, J.J. Effects of polyurethane foams on microbial growth in fuel-water systems. Appl. Microbiol. 1969, 17, 227-231. [PubMed]

22. Turley, P.A.; Fenn, R.J.; Ritter, J.C. Pyrithiones as antifoulants: Environmental chemistry and preliminary risk assessment. Biofouling 2000, 15, 175-182. [CrossRef] [PubMed] 
23. Gibson, W.T.; Hardy, W.S.; Groom, M.H. The effect and mode of action of zinc pyrithione on cell growth. II. In vitro studies. Food Chem. Toxicol. 1985, 23, 103-110. [CrossRef]

24. Santa, A.M.; Pozuelo, J.M.; López, A.; Sanz, F. Toxicity of potential irritants in mammalian cells in vitro. Ecotoxicol. Environ. Saf. 1996, 34, 56-58.

25. Fonseca, A.J.; Pina, F.; Macedo, M.F.; Leal, N.; Romanowska-Deskins, A.; Laiz, L.; Gómez-Bolea, A.; Saiz-Jimeneze, C. Anatase as an alternative application for preventing biodeterioration of mortars: Evaluation and comparison with other biocides. Int. Biodeterior. Biodegrad. 2010, 64, 388-396. [CrossRef]

26. Markowska-Szczupak, A.; Ulfig, K.; Morawski, A.W. The application of titanium dioxide for deactivation of bio-particulates: An overview. Catal. Today 2011, 169, 249-257. [CrossRef]

27. Caballero, L.; Whitehead, K.A.; Allen, N.S.; Verran, J. Photo inactivation of Escherichia coli on acrylic paint formulations using fluorescent light. Dyes Pigm. 2010, 86, 56-62. [CrossRef]

28. Moafi, H.F.; Shojaie, A.F.; Zanjanchi, M.A. Semiconductor-assisted self-cleaning polymeric fibers based on zinc oxide nanoparticles. J. Appl. Polym. Sci. 2011, 121, 3641-3650. [CrossRef]

29. Peng, Y.; Ji, J.; Zhao, X.; Wan, H.; Chen, D. Preparation of ZnO Nano powder by a novel ultrasound assisted non-hydrolytic sol-gel process and its application in photo-catalytic degradation of C.I. Acid Red 249. Powder Technol. 2013, 233, 325-330. [CrossRef]

30. Roach, P.; Shirtcliffe, N.J.; Newton, M.I. Progress in super hydrophobic surface development. Soft Matter 2008, 4, 224-240. [CrossRef]

31. Grant, C.; Hunter, C.A.; Flannigan, B.; Bravery, A.F. The moisture requirements of moulds isolated from domestic dwellings. Int. Biodeterior. 1989, 25, 259-284. [CrossRef]

32. Ezeonu, I.M.; Noble, J.A.; Simmons, R.B.; Price, D.L.; Crow, S.A.; Ahearn, D.G. Effect of relative humidity on fungal colonization of fiber glass insulation. Appl. Environ. Microbiol. 1994, 60, 2149-2151. [PubMed]

33. Viitanen, H. Factors affecting the development of biodeterioration in wooden constructions. Mater. Struct. 1994, 27, 483-493. [CrossRef]

34. Chang, J.C.; Foarde, K.K.; Vanosdell, D.W. Growth evaluation of fungi (Penicillium and Aspergillus spp.) on ceiling tiles. Atmos. Environ. 1995, 29, 2331-2337. [CrossRef]

35. Chang, J.C.; Foarde, K.K.; VanOsdell, D.W. Assessment of fungal (Penicillium chrysogenum) growth on three HVAC duct materials. Environ. Int. 1996, 22, 425-431. [CrossRef]

36. Flannigan, B.; Morey, P.R. Control of Moisture Problems Affecting Biological Indoor Air Quality; International Society of indoor Air Quality and Climate: Ottawa, ON, Canada, 1996.

37. Foarde, K.K.; VanOsdell, D.W.; Chang, J.C.S. Evaluation of fungal growth on berglass duct materials for various moisture, soil, use, and temperature conditions. Indoor Air 1996, 6, 83-92. [CrossRef]

38. Mallows, C.L. Some comments on C . Technometrics 1973, 15, 661-675.

39. Akaike, $\mathrm{H}$. Information theory and an extension of maximum likelihood principle. In Proceedings of the $2 \mathrm{nd}$ International Symposium on Information Theory, Tsahkadsor, Armenia, 2-8 September 1971; Petrov, B.N., Caski, F., Eds.; Akadémiai Kiado: Budapest, Hungary, 1973; pp. 267-281.

40. ASTM D1210-05 Standard Test Method for Fineness of Dispersion of Pigment-Vehicle Systems by Hegman-Type Gage; ASTM International: Bethesda, MD, USA, 2010.

41. ASTM D3719-00 Standard Test Method for Quantifying Dirt Collection on Coated Exterior Panels; ASTM International: Bethesda, MD, USA, 2000.

42. Rasband, W. ImageJ. U.S. National Institutes of Health. Available online: https://imagej.nih.gov/ij/ (accessed on 26 November 2018).

43. Chatterjee, S.; Hadi, A.S. Regression Analysis by Example, 4th ed.; John Wiley \& Sons: Hoboken, NJ, USA, 2015.

44. Mendenhall, W.; Sincich, T. Simple linear regression. In A Second Course in Statistics: Regression Analysis, 7th ed.; Prentice Hall: Boston, MA, USA, 2012; pp. 104-105.

(C) 2018 by the authors. Licensee MDPI, Basel, Switzerland. This article is an open access article distributed under the terms and conditions of the Creative Commons Attribution (CC BY) license (http://creativecommons.org/licenses/by/4.0/). 